Research Article

\title{
Synthesis and Characterization of Mesoporous Carbon Supported Ni-Ga Catalyst for Low-Pressure $\mathrm{CO}_{2}$ Hydrogenation
}

\author{
Uwin Sofyani, Yuni K. Krisnandi, Iman Abdullah*
}

Solid Inorganic Framework Laboratory, Department of Chemistry, Faculty of Mathematics and Natural Sciences (FMIPA), Universitas Indonesia, Depok-16424, Indonesia.

Received: $7^{\text {th }}$ January 2022; Revised: 22 ${ }^{\text {nd }}$ February 2022; Accepted: $23^{\text {rd }}$ February 2022 Available online: $2^{\text {nd }}$ March 2022; Published regularly: June 2022

\section{Abstract}

In this study, the atmospheric-pressure hydrogenation of $\mathrm{CO}_{2}$ was carried over bimetallic Ni-Ga catalyst supported on mesoporous carbon (MC). MC was successfully prepared using the soft-template method as proven by Fourier Transform Infra Red (FTIR), X-ray Diffraction (XRD), Scanning Electron Microscopy - Energy Dispersive X-Ray Spectroscopy (SEM-EDS), Brunauer-Emmett-Teller Surface Area Analyzer (BET SAA), and Transmission Electron Microscopy (TEM) characterizations. The Ni-Ga/MC catalyst was synthesized using the impregnation method, and based on the XRD characterization, the formation of bimetallic Ni-Ga on the MC support is confirmed. The EDS mapping image shows the uniform distribution of the bimetallic Ni-Ga on the MC surface, especially for the $\mathrm{Ni}_{5} \mathrm{Ga}_{3} / \mathrm{MC}$ and $\mathrm{NiGa}_{3} / \mathrm{MC}$ catalysts. Moreover, the TEM images show an excellent pore size distribution. The formation of Ni-Ga alloy was identified as an active site in the $\mathrm{CO}_{2}$ hydrogenation. $\mathrm{Ni}_{5} \mathrm{Ga}_{3} / \mathrm{MC}$ catalyst exhibited a $10.80 \%$ conversion of $\mathrm{CO}_{2}$ with $588 \mathrm{\mu mol} / \mathrm{g}$ formaldehyde at $1 \mathrm{~atm}, 200{ }^{\circ} \mathrm{C}$, and $\mathrm{H}_{2} / \mathrm{CO}_{2}$ ratio of $3 / 1$.

Copyright (C) 2022 by Authors, Published by BCREC Group. This is an open access article under the CC BY-SA License (https://creativecommons.org/licenses/by-sa/4.0).

Keywords: $\mathrm{CO}_{2}$ Hydrogenation; Bimetallic catalyst; Ni-Ga; Mesoporous Carbon

How to Cite: U. Sofyani, Y.K. Krisnandi, I. Abdullah (2022). Synthesis and Characterization of Mesoporous Carbon Supported Ni-Ga Catalyst for Low-Pressure $\mathrm{CO}_{2}$ Hydrogenation. Bulletin of Chemical Reaction Engineering \& Catalysis, 17(2), 278-285 (doi: 10.9767/bcrec.17.2.13377.278-285)

Permalink/DOI: https://doi.org/10.9767/bcrec.17.2.13377.278-285

\section{Introduction}

$\mathrm{CO}_{2}$ is a greenhouse gas that is responsible for global warming. On the other hand, $\mathrm{CO}_{2}$ hydrogenation is the reaction that can produce methanol, dimethyl ether (DME), formic acid, and also formaldehyde [1,2]. Therefore, $\mathrm{CO}_{2}$ hydrogenation is beneficial in mitigating global warming and provides value-added chemical products. Unfortunately, the very stable and inert nature of $\mathrm{CO}_{2}$ makes it difficult to react, so

\footnotetext{
* Corresponding Author.

Email: iman.abdullah@sci.ui.ac.id (I. Abdullah)

Telp: +62-856-7735857
}

$\mathrm{CO}_{2}$ activation requires a high-energy substance at high pressure. In addition, direct hydrogenation will produce water product and an undesired reverse water gas shift (rWGS) reaction. The formation of excess water can interfere with the product hydrogenation and indicate the decrease of catalyst performance. Therefore, an active and selective catalyst is highly needed for an effective and efficient reaction.

A new type of catalyst, a mixture of two metals or bimetal, was reported to have good activity and selectivity for $\mathrm{CO}_{2}$ hydrogenation at atmospheric pressure [3]. Studt et al. [4], in 2014, firstly reported that the $\mathrm{Ga}_{3} \mathrm{Ni}_{5}$ catalyst has 
good activity, selectivity, and stability for the $\mathrm{CO}_{2}$ conversion with $100 \%$ selectivity of methanol and DME at atmospheric pressure. Good selectivity of $\mathrm{Ni}_{5} \mathrm{Ga}_{3}$ catalyst for methanol production is also reported [5-7]. The catalytic activity of a catalyst can be increased by supporting the catalyst. Many previous studies have reported silica and alumina as support materials in the $\mathrm{CO}_{2}$ hydrogenation to methanol [8]. No studies have reported the application of mesoporous carbon (MC) as Ni-Ga support. MC has characteristics that greatly assist its function as a catalyst support material. These characteristics are high chemical, mechanical, thermal stability, and also it is widely available in nature. In addition, MC has a controlled and stable pore structure that makes it possible to disperse the active phase [9]. The application of $\mathrm{MC}$ as catalyst support has been widely reported [10-12]. Recently, our research group has reported the good performance of the $\mathrm{Ni}$ phenanthroline complex supported on $\mathrm{MC}$ as a catalyst in the $\mathrm{CO}_{2}$ carboxylation with phenylacetylene under atmospheric pressure [13].

In this work, we investigate the atmospheric-pressure hydrogenation of $\mathrm{CO}_{2}$ using the $\mathrm{Ni}$ Ga catalyst supported by MC. The support and the series of catalysts were synthesized using a soft-template and impregnation method, respectively. The catalytic performance $\mathrm{Ni}$ $\mathrm{Ga} / \mathrm{MC}$ catalyst was also compared with $\mathrm{Ni} / \mathrm{MC}$ and $\mathrm{Ga} / \mathrm{MC}$. The hydrogenation reaction was carried out in a fixed-bed tubular reactor at low-atmospheric pressure with $\mathrm{H}_{2}$ to $\mathrm{CO}_{2}$ molar ratio of $3: 1$ by varying reaction temperature at $150{ }^{\circ} \mathrm{C}, 170{ }^{\circ} \mathrm{C}, 200{ }^{\circ} \mathrm{C}$, and $250{ }^{\circ} \mathrm{C}$. The lowpressure condition was chosen because it has several advantages over the reaction at high pressure, such as a simpler process, lower cost and more applicable to small scale equipment [4]. In addition, by selecting the hydrogenation reaction conditions at lower pressures, it is also possible to shift the hydrogenation products towards the formation of products with lower reduction states, such as formaldehyde. This is interesting to investigate, considering the many uses of formaldehyde as a precursor in various chemical industries, as well as to provide an alternative pathway for formaldehyde synthesis.

\section{Materials and Methods}

\subsection{Materials}

Phloroglucinol, Pluronic F-127, gallium (III) nitrate were provided by Sigma Aldrich. Nickel (II) nitrate and ethanol $(99 \% \mathrm{v} / \mathrm{v})$ were obtained from Merck (Germany). Hydrochloric acid
$(\mathrm{HCl})(37 \% \mathrm{v} / \mathrm{v})$ and formaldehyde $(37 \% \mathrm{v} / \mathrm{v})$ were acquired from PT. Smart Lab Indonesia (Jakarta), distilled water was purchased from CV Satya Darmawan. High purity gases: hydrogen, nitrogen, carbon dioxide, and argon were procured from CV Retno Gas.

\subsection{Methods}

\subsubsection{MC support synthesis}

The soft-template method synthesized MC support, adopted from previously reported studies $[12,14]$. Briefly, phloroglucinol and pluronic F-127 were solvated in the mixture of water and ethanol 9:10 (w/w) at room temperature. After the copolymer was utterly dissolved, $37 \%(\mathrm{w} / \mathrm{w}) \mathrm{HCl}$ was appended to the mixture, then 30 minutes stirred. Under continuously stirring, the mixture was added by $37 \%(\mathrm{w} / \mathrm{w})$ formaldehyde. After 1-2 hours, the two layers will form, and then the base layer was taken and stirred for 12 hours. The decantation monolith was then cured in an autoclave for 24 hours at $100{ }^{\circ} \mathrm{C}$. The next step is carbonizing the material in a tubular furnace under $\mathrm{N}_{2}$ flow with the following conditions: a temperature of $100-400^{\circ} \mathrm{C}, 400-850^{\circ} \mathrm{C}$, and $850^{\circ} \mathrm{C}$ with the heating rate of $1{ }^{\circ} \mathrm{C} / \mathrm{min}, 5^{\circ} \mathrm{C} / \mathrm{min}$, and kept at 2 hours, respectively. Under $\mathrm{N}_{2}$ flow, carbonized $\mathrm{MC}$ cooled down to room temperature.

\subsubsection{Catalyst preparation}

The series of Ni-Ga/MC catalysts were prepared using the incipient wetness impregnation method. A mixed Ni nitrate and Ga nitrate solution were sprayed onto the $\mathrm{MC}$ to form a paste. The paste was dried at room temperature, then an aqueous solution of Ni-Ga nitrate was resprayed. This step is repeated until the aqueous solution of $\mathrm{Ni}-\mathrm{Ga}$ nitrate is used up. Next, the sample catalyst was aged for 24 hours. After that, the catalyst sample was reduced under $\mathrm{H}_{2}$ flow at $700{ }^{\circ} \mathrm{C}$ for $2 \mathrm{~h}$. Aqueous solutions of Ni nitrate and Ga nitrate were varied at the molar ratios of $\mathrm{Ni} / \mathrm{Ga}(1 / 3,3 / 3$, and $5 / 3$ ) with a total metal loading of $30 \%$ of the MC. For comparison, $\mathrm{Ni} / \mathrm{MC}$ and $\mathrm{Ga} / \mathrm{MC}$ were also prepared by the same procedure. The pre-

Table 1. Prepared catalysts

\begin{tabular}{ccc}
\hline No & Molar Ratio Ni/Ga & Catalysts \\
\hline 1 & $5 / 3$ & $\mathrm{Ni}_{5} \mathrm{Ga}_{3} / \mathrm{MC}$ \\
2 & $3 / 3$ & $\mathrm{NiGa}^{\mathrm{MC}}$ \\
3 & $1 / 3$ & $\mathrm{NiGa}_{3} / \mathrm{MC}$ \\
4 & - & $\mathrm{Ni} / \mathrm{MC}$ \\
5 & - & $\mathrm{Ga} / \mathrm{MC}$ \\
\hline
\end{tabular}


pared catalyst abbreviations are presented in Table 1.

\subsubsection{Catalyst characterizations}

Functional groups and absorption spectra of material were characterized by Alpha Bruker FTIR spectrometer using $\mathrm{KBr}$ pellet. The XRD pattern measurement was performed with an XRD PANalytical: X'Pert Pro XRD 2318 under $\mathrm{Cu}-\mathrm{K} a 1.54 \AA$ radiation. The instrument was operated at $30 \mathrm{~mA}$ and $40 \mathrm{kV}$ with a time perstep 0.02. The surface area of support and catalysts was analyzed on a Surface Area Analyzer (SAA) Quantachrom QuadraWin (C2000-16 Surface Area and Pore Analyzer at 77.3 K. SEMEDS mapping was investigated using SEMEDS Hitachi SU-3500. TEM images were collected using the FEI Tecnai D2360 SuperTwin electron microscope operating at $200 \mathrm{kV}$ acceleration voltage.

\subsubsection{Catalytic activity test}

The catalytic activity was analyzed at atmospheric pressure in a tubular fixed-bed reactor. The catalyst bed volume was $1.17 \mathrm{~cm}^{3}$. The resulting products were analyzed using gas chromatography (GC) equipped with Porapak$\mathrm{Q}$ and RTX-1 column connected to a thermal conductivity detector (TCD) and Flame Ionization Detector (FID), respectively. $\mathrm{CO}_{2}$ conversion was investigated using GC Shimadzu TCD-8A. Meanwhile, the product hydrogenation was analyzed using GC Shimadzu FID

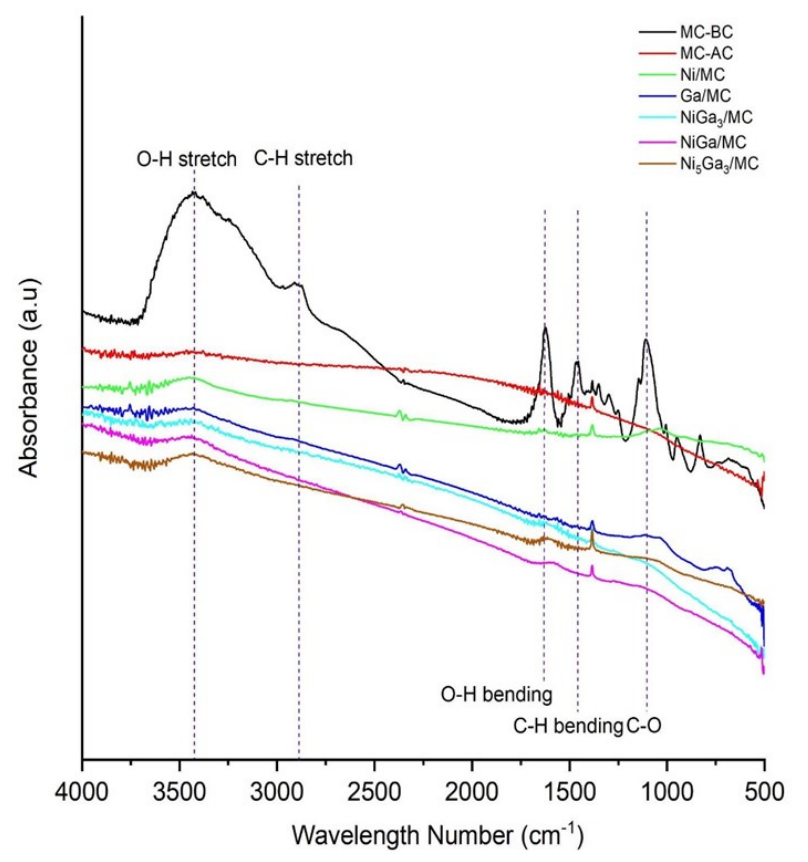

Figure 1. FTIR Spectra of MC and Ni-Ga/MC.
2014. The injector, column, and detector temperature of TCD were set up at $100{ }^{\circ} \mathrm{C}, 60^{\circ} \mathrm{C}$, and $100^{\circ} \mathrm{C}$, respectively. As for FID is $200{ }^{\circ} \mathrm{C}$, $150{ }^{\circ} \mathrm{C}$, and $200{ }^{\circ} \mathrm{C}$, respectively. The carrier gas for the injected sample inside the GC TCD and FID was argon and nitrogen, respectively.

\section{Results and Discussion}

\subsection{Catalyst Characterizations}

Functional groups and absorption spectra of $\mathrm{MC}$ and MC supported Ni-Ga catalyst were investigated by FTIR, as shown in Figure 1. The resulting characterization of MC before carbonization (MC-BC) shows several peaks at 3400 $\mathrm{cm}^{-1}, 2900 \mathrm{~cm}^{-1}, 1625 \mathrm{~cm}^{-1}, 1462 \mathrm{~cm}^{-1}$, and $1100 \mathrm{~cm}^{-1}$ that indicate the functional group of $\mathrm{O}-\mathrm{H}$ stretch, $\mathrm{C}-\mathrm{H}$ stretch, $\mathrm{O}-\mathrm{H}$ bending, $\mathrm{C}-\mathrm{H}$ bending, and $\mathrm{C}-\mathrm{O}$ bending, respectively. These peaks are attributed to the remaining F-127 template and phloroglucinol precursor. However, the disappearing peaks in the MC spectrum after carbonization (MC-AC) indicate that the carbonization has been conducted successfully. The same spectrum of MC-AC was also seen in $\mathrm{Ni} / \mathrm{MC}, \mathrm{Ga} / \mathrm{MC}, \mathrm{NiGa}_{3} / \mathrm{MC}, \mathrm{NiGa} / \mathrm{MC}$, and $\mathrm{Ni}_{5} \mathrm{Ga}_{3} / \mathrm{MC}$, indicating that metal impregnation did not affect the MC support. However, this needs to be further confirmed with other characterizations.

XRD patterns of MC support and MC supported Ni-Ga catalyst are pointed in Figure 2. Two peaks of MC at $2 \theta=24.05^{\circ}(002)$ and $43.56^{\circ}$ (100) reveal the presence of graphite

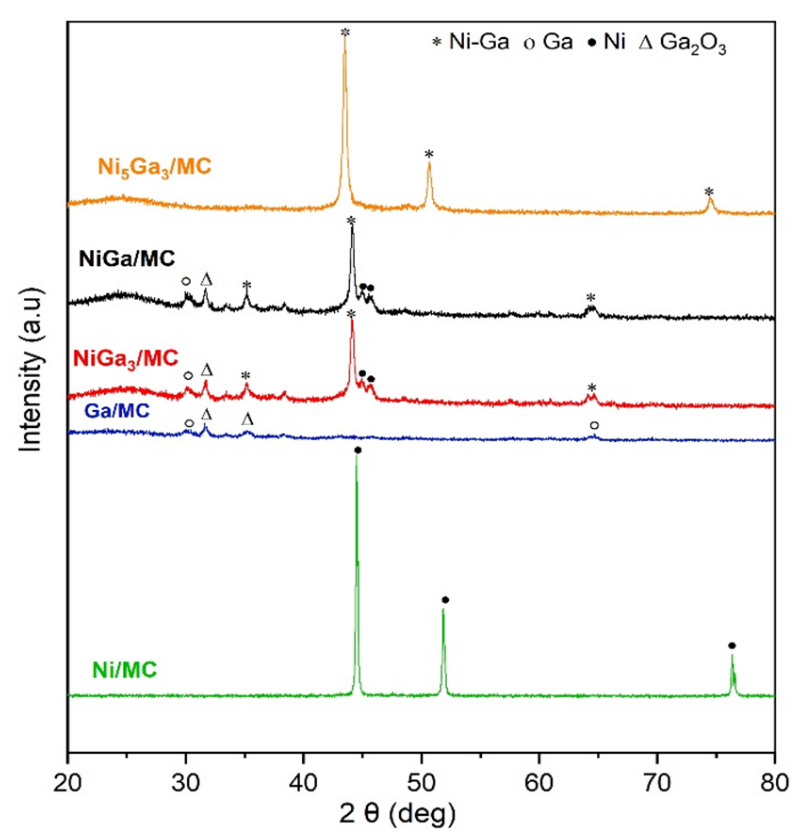

Figure 2. X-Ray diffractogram of $\mathrm{MC}$ and Ni$\mathrm{Ga} / \mathrm{MC}$. 


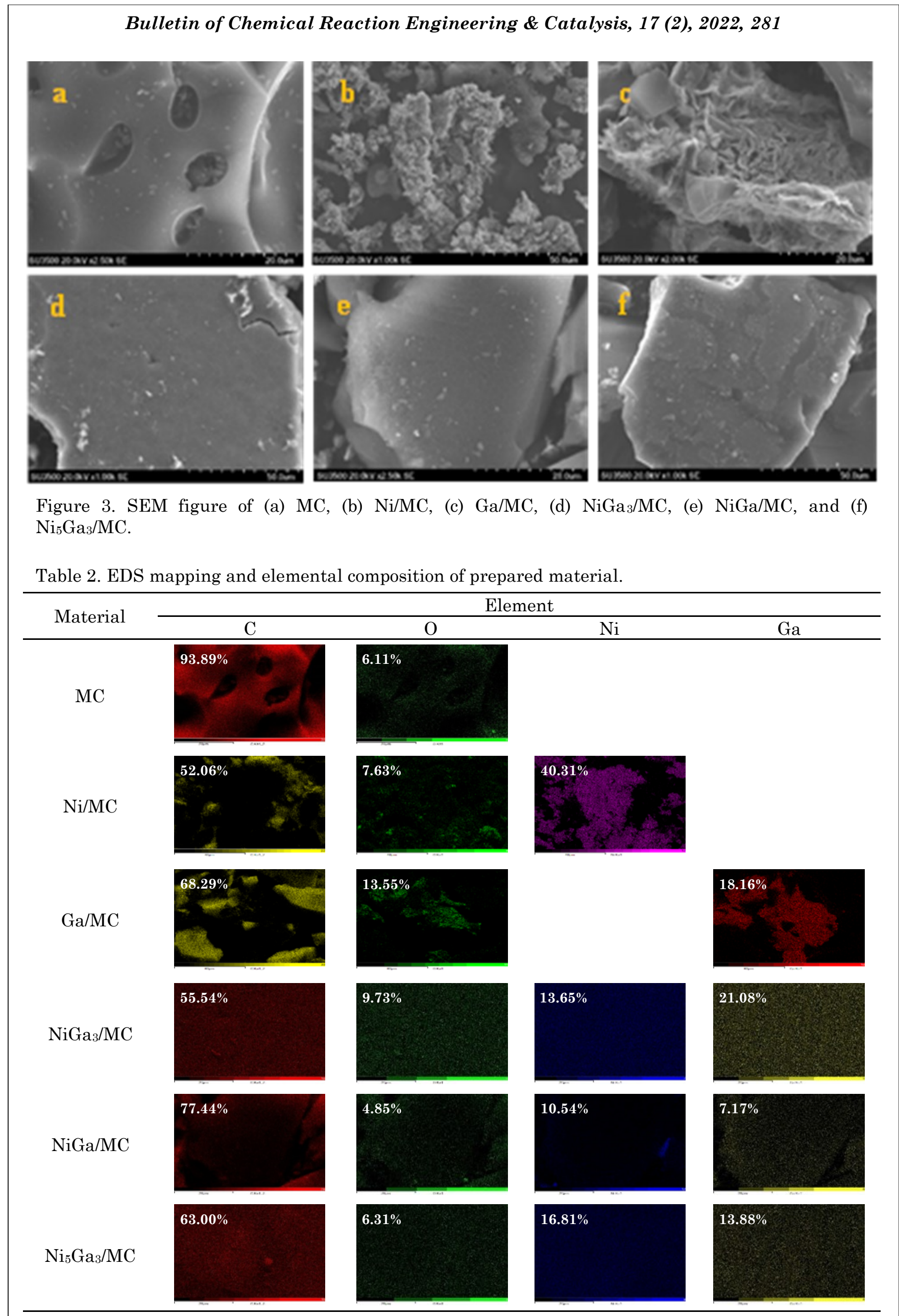


carbon $[15,16]$ and the widened diffraction peaks are attributed to the amorphous phase of MC. The Ni-Ga peaks are shown at $35.20^{\circ}$, $44.18^{\circ}, 64.40^{\circ}$ for $\mathrm{NiGa}_{3} / \mathrm{MC}[5]$; $35.20^{\circ}, 44.18^{\circ}$, $64.40^{\circ}$ for $\mathrm{NiGa} / \mathrm{MC}[4]$, and $43.49^{\circ}, 50.71^{\circ}$, $74.55^{\circ}$ for $\mathrm{Ni}_{5} \mathrm{Ga}_{3} / \mathrm{MC}$ [4-6]. $\mathrm{Ni}_{5} \mathrm{Ga}_{3} / \mathrm{MC}$ shows good crystallinity. The indication of partial oxidation in $\mathrm{NiGa}$ and $\mathrm{NiGa}_{3}$ can be observed at $2 \theta=31.67^{\circ}$ (JCPDS No 11-0370), which is a footprint of small gallium oxide formation [17]. Moreover, the peak at $30.10^{\circ}$ in $\mathrm{NiGa}$ and $\mathrm{Ni}$ $\mathrm{Ga}_{3}$ is attributed to $\mathrm{Ga}(0)$ reported at PDF No 05-0601 [18]. As a comparison, Ga/MC exhibited $2 \theta$ at $30.10^{\circ}, 64.57^{\circ}$ that corresponds to the presence of $\mathrm{Ga}(0)$, and peaks at $31.67^{\circ}$ and $35.37^{\circ}$ for $\mathrm{Ga}_{2} \mathrm{O}_{3}$ [17]. For Ni/MC, diffraction

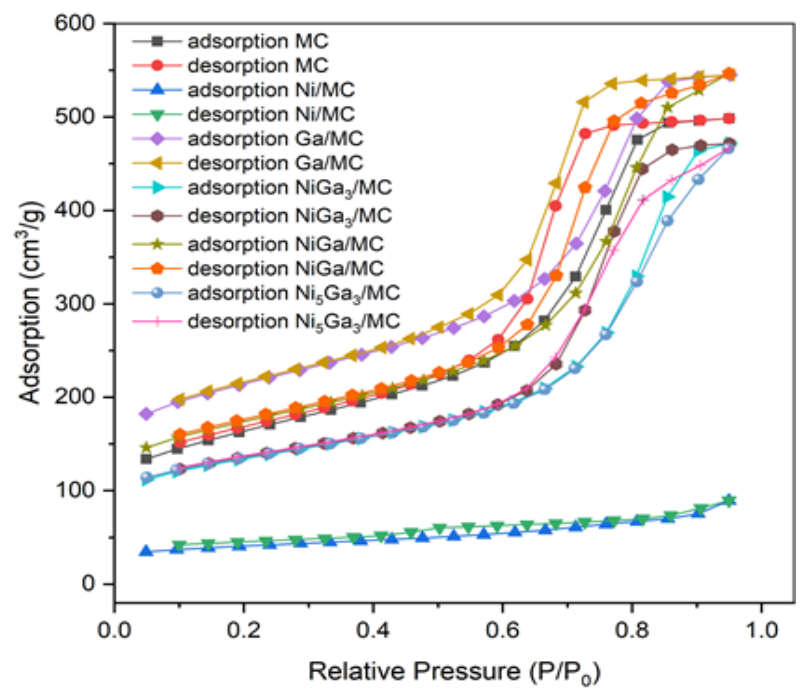

peaks at $44.69^{\circ}(111), 51.72^{\circ}(200), 76.3^{\circ}(220)$ corresponding to $\mathrm{Ni}(0)$, based on PDF No.04$0850[10,19]$.

The morphologies and elemental composition of $\mathrm{MC}, \mathrm{Ni} / \mathrm{MC}, \mathrm{Ga} / \mathrm{MC}, \mathrm{NiGa}_{3} / \mathrm{MC}, \mathrm{Ni}$ $\mathrm{Ga} / \mathrm{MC}$, and $\mathrm{Ni}_{5} \mathrm{Ga}_{3} / \mathrm{MC}$ were investigated by SEM-EDS, as shown in Figure 3. The MC shows a smooth morphology, both Ni/MC and $\mathrm{Ga} / \mathrm{MC}$ present rough surfaces. $\mathrm{NiGa}_{3} / \mathrm{MC}, \mathrm{Ni}$ $\mathrm{Ga} / \mathrm{MC}$, and $\mathrm{Ni}_{5} \mathrm{Ga}_{3} / \mathrm{MC}$ show a slightly rough surface with white dots, corresponding to the impregnated metal into and/or spread out on the MC surface. The results of mapping and elemental composition are summarized in Table 2. The concentration of carbon in parent MC is $98.89 \%$, then after metal impregnation,

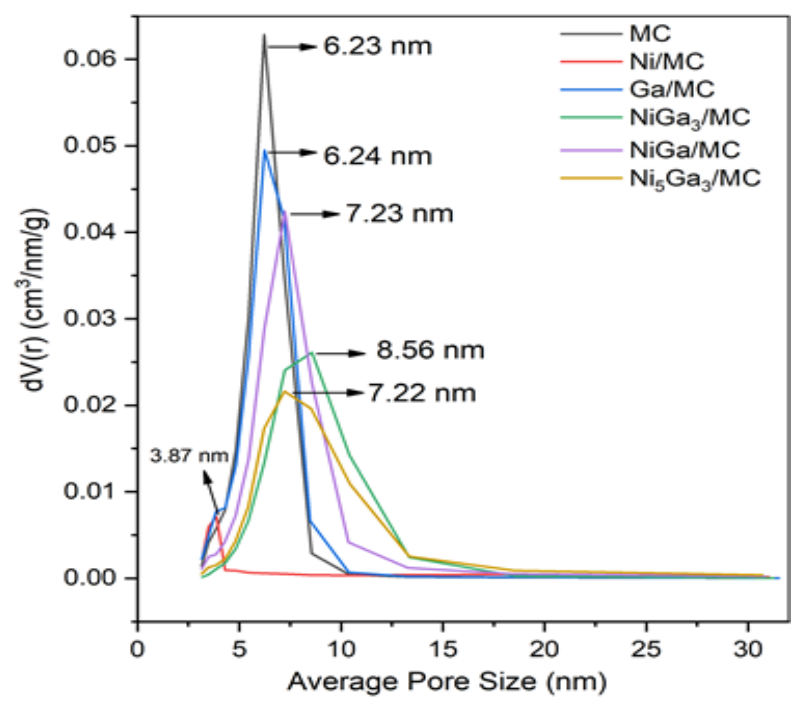

Figure 4. Surface area analysis of prepared material, (a) $\mathrm{N}_{2}$ adsorption-desorption isotherm and (b) pore size distribution.
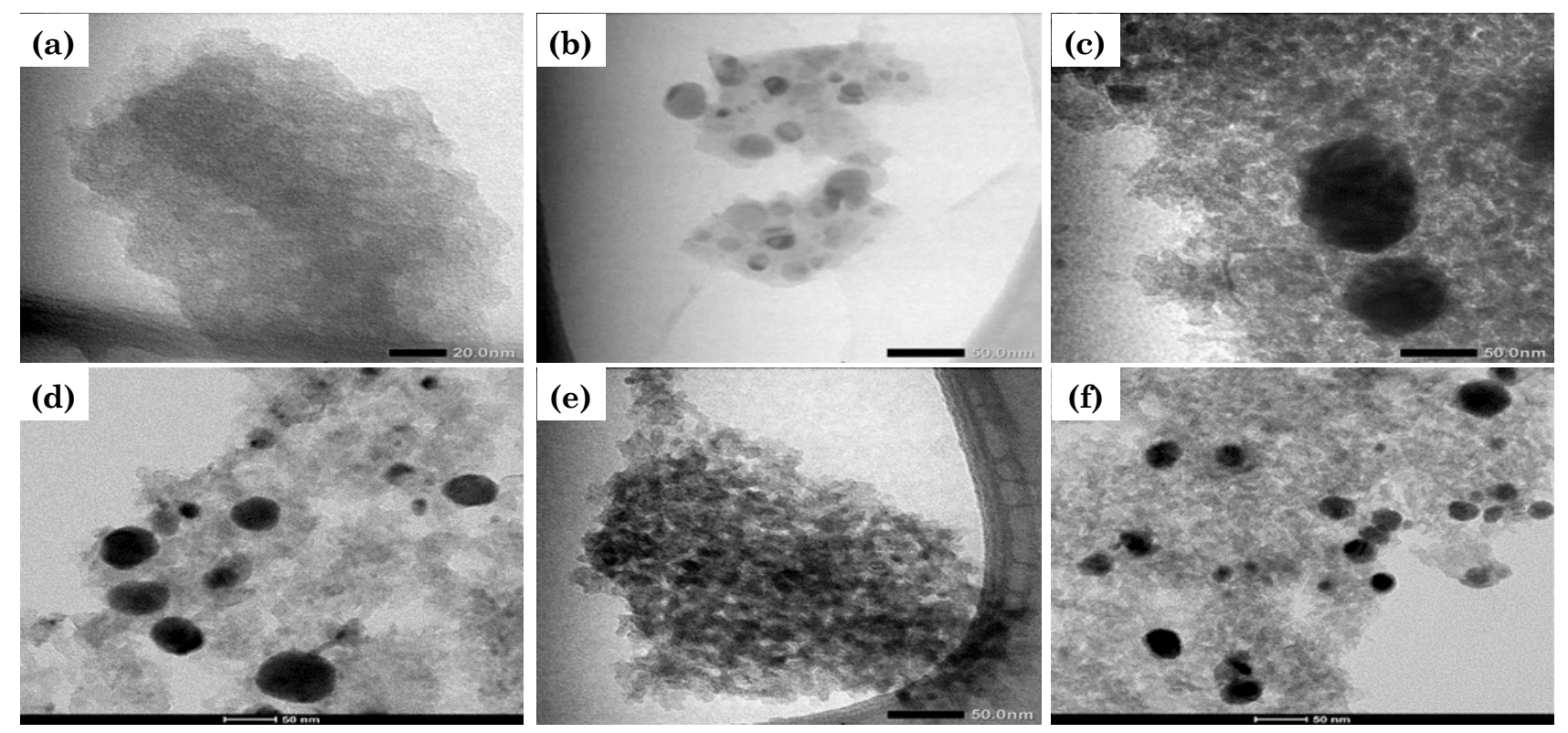

Figure 5. TEM image of prepared material (a) MC, (b) Ni/MC, (c) Ga/MC, (d) NiGa $/ \mathrm{MC}$, (e) Ni$\mathrm{Ga} / \mathrm{MC}$, and (f) $\mathrm{Ni}_{5} \mathrm{Ga}_{3} / \mathrm{MC}$. 
it decreased to $52.06-77.44 \%$ while the number of metals was detected. This phenomenon indicates the successful impregnation of the metal in $\mathrm{MC}$.

Figure 4 shows the BET-SAA analysis on $\mathrm{MC}$ and MC-supported Ni-Ga catalysts. The $\mathrm{N}_{2}$ adsorption-desorption isotherms of all materials exhibit the isotherm type IV, a distinct hysteresis loop points to mesoporosity in the materials. The average pore size distribution of support and the series of catalysts investigated by the BJH method show mesoporous material characteristics $(2-50 \mathrm{~nm})$. A remarkably large surface area of MC $\left(599.00 \mathrm{~m}^{2} / \mathrm{g}\right)$ was obtained in this study, which then decreased after modification in $\mathrm{Ni} / \mathrm{MC}\left(139 \mathrm{~m}^{2} / \mathrm{g}\right), \mathrm{NiGa}_{3} / \mathrm{MC}(446$ $\mathrm{m}^{2} / \mathrm{g}$ ), and $\mathrm{Ni}_{5} \mathrm{Ga}_{3} / \mathrm{MC}\left(456 \mathrm{~m}^{2} / \mathrm{g}\right)$, indicating that metals have successfully impregnated to the channel of MC. On the other hand, the surface area of $\mathrm{Ga} / \mathrm{MC}\left(699 \mathrm{~m}^{2} / \mathrm{g}\right)$ and NiGa/MC $\left(571 \mathrm{~m}^{2} / \mathrm{g}\right)$ were larger than the parent MC, suggesting that the impregnated metals also resided on the surface of MC to form new nanoclusters. TEM analysis on the catalysts (Figure 5) support this finding. The parent MC shows a worm-hole-like structure [14], while in the $\mathrm{Ni} / \mathrm{MC}$, the metals (Figure 5(b)) are well dispersed into the pores (blackish spots), while in $\mathrm{Ga} / \mathrm{MC}$ (Figure 5(c)), the metals grow as nanoclusters outside the surface. Interestingly, in $\mathrm{NiGa}_{3} / \mathrm{MC}$ and $\mathrm{Ni}_{5} \mathrm{Ga}_{3} / \mathrm{MC}$ catalysts, the metals grow inside and outside the pores. The profile of $\mathrm{NiGa} / \mathrm{MC}$ is somewhat similar to that of Ga/MC. All catalysts show the metal size ranging less than $10 \mathrm{~nm}$.

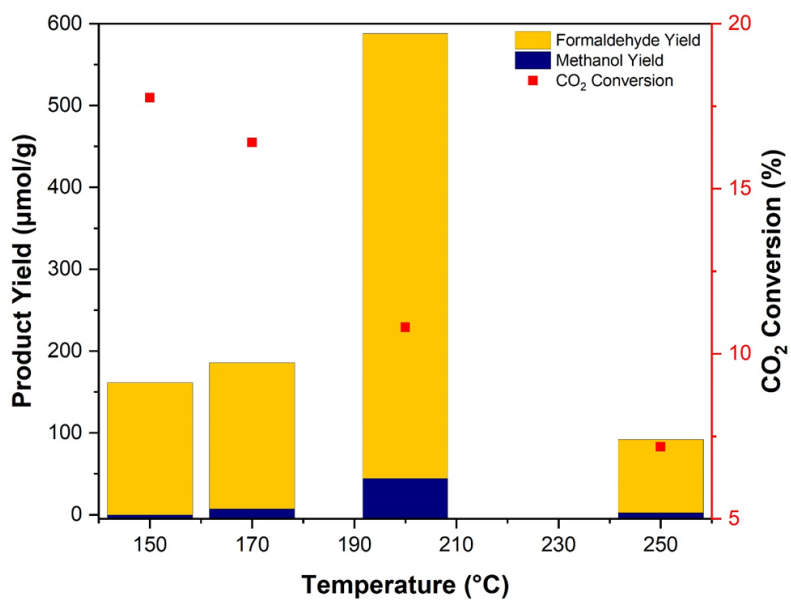

Figure 6. Temperature screening for $\mathrm{CO}_{2}$ hydrogenation using $\mathrm{Ni}_{5} \mathrm{Ga}_{3} / \mathrm{MC}$ catalyst. Reaction condition $\mathrm{P}=1 \mathrm{~atm}, \mathrm{H}_{2}: \mathrm{CO}_{2}$ molar ratio $=3: 1, \mathrm{~T}=150-250^{\circ} \mathrm{C}$.

\subsection{Catalyst Activity Test}

Since the $\mathrm{Ni}_{5} \mathrm{Ga}_{3} / \mathrm{MC}$ catalyst shows superior physicochemical properties than other asprepared catalysts (e.g. well-formation and well-dispersed metals on the support, high crystallinity, and large surface area), it was used to optimize the condition of the catalytic reaction of $\mathrm{CO}_{2}$ reduction. The catalyst activity was determined from the conversion of $\mathrm{CO}_{2}$, yield $(\mu \mathrm{mol} / \mathrm{g})$, and product selectivity. Based on the analysis of the reaction products using GC-FID, it is known that formaldehyde is the major product of the $\mathrm{CO}_{2}$ hydrogenation reaction, accompanied by the presence of small amounts of methanol. Figure 6 shows the effect of the working temperature on the reaction. The highest conversion of $\mathrm{CO}_{2}$ and the yield of formaldehyde $(10.80 \%$ and $588 \mu \mathrm{mol} / \mathrm{g})$ are observed at the reaction at $200{ }^{\circ} \mathrm{C}$, while in the reaction occurring below $200{ }^{\circ} \mathrm{C}$, the energy given is not enough to initiate the reaction; at over $200{ }^{\circ} \mathrm{C}$, the reaction direction returns to the reactants. This is related to the exothermic reaction of $\mathrm{CO}_{2}$ hydrogenation $\left(\Delta \mathrm{H}_{298 \mathrm{~K}}=-49.5\right.$ $\mathrm{kJ} / \mathrm{mol}$ to methanol and $-42.55 \mathrm{~kJ} / \mathrm{mol}$ to formaldehyde). As suggested by Zhou et al. [20] that the hydrogenation reaction of $\mathrm{CO}_{2}$ took place following the mechanism pathways: $\mathrm{CO}_{2}$ will be consecutively reduced to formic acid, formaldehyde, methanol and methane.

At the optimum reaction temperature, 200 ${ }^{\circ} \mathrm{C}$, the catalyst activity test was carried out using $\mathrm{MC}, \mathrm{Ni} / \mathrm{MC}, \mathrm{Ga} / \mathrm{MC}, \mathrm{NiGa} / \mathrm{MC}, \mathrm{NiGa}_{3} / \mathrm{MC}$, and the results are exhibited in Figure 7. MC was proven to be an inactive catalyst with the low conversion of $\mathrm{CO}_{2}$ due to adsorption on the mesoporous carbon surface. All other tested

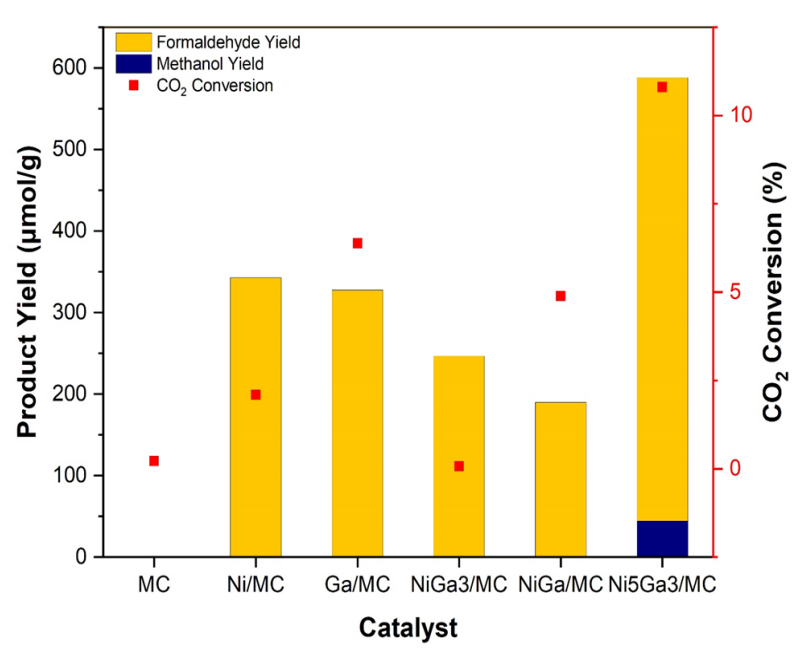

Figure 7. $\mathrm{CO}_{2}$ hydrogenation over prepared catalysts. Reaction condition $\mathrm{P}=1 \mathrm{~atm}$, $\mathrm{H}_{2}: \mathrm{CO}_{2}$ molar ratio $=3: 1, \mathrm{~T}=200{ }^{\circ} \mathrm{C}$. 
catalysts show $100 \%$ formaldehyde selectivity, except for $\mathrm{Ni}_{5} \mathrm{Ga}_{3} / \mathrm{MC}(588 \mu \mathrm{mol} / \mathrm{g}$ formaldehyde, $44.38 \mu \mathrm{mol} / \mathrm{g}$ methanol or $93 \%$ formaldehyde selectivity). Among the three Ni-Ga catalysts, $\mathrm{Ni}_{5} \mathrm{Ga}_{3} / \mathrm{MC}$ provides the highest $\mathrm{CO}_{2}$ conversion and product yield. Likewise, when compared with monometallic catalysts $(\mathrm{Ni} / \mathrm{MC}$ and $\mathrm{Ga} / \mathrm{MC}$ ). This result is related to the catalyst characteristics as previously described that $\mathrm{Ni}_{5} \mathrm{Ga}_{3} / \mathrm{MC}$ has a good crystallinity of the $\delta$ $\mathrm{Ni}_{5} \mathrm{Ga}_{3} / \mathrm{MC}$ phase, which has been previously reported as the active $\mathrm{Ni}-\mathrm{Ga}$ phase on $\mathrm{CO}_{2}$ hydrogenation. In addition, $\mathrm{Ni}_{5} \mathrm{Ga}_{3} / \mathrm{MC}$ also has a high surface area with a uniform metal distribution as previously shown in SAA-BET results in Figure 4 and TEM image in Figure 5. In term of pore size and distribution, the $\mathrm{Ni}_{5} \mathrm{Ga}_{3} / \mathrm{MC}$ catalyst also shows a wide pore size with a uniform distribution within the range of $5-13 \mathrm{~nm}$ with an average pore size of $7.22 \mathrm{~nm}$. These properties support its good catalytic activity in converting $\mathrm{CO}_{2}$ to formaldehyde and methanol even at ambient pressure. The catalytic test also showed that when in the right ratio (i.e. 5:3), $\mathrm{Ni}$ and Ga gave a synergistic effect that increased product formation, in which the $\mathrm{Ni}_{5} \mathrm{Ga}_{3} / \mathrm{MC}$ catalyst gave formaldehyde yields almost twice the formaldehyde yields given by monometallic $\mathrm{Ni} / \mathrm{MC}$ or $\mathrm{Ga} / \mathrm{MC}$ catalysts.

The $\mathrm{CO}_{2}$ hydrogenation reaction mechanism on a Ni-Ga/MC catalyst is shown in Figure 8. According to Ahmad \& Upadhyayula [7], the catalyst's active site, either $\mathrm{Ni}$ or $\mathrm{Ga}$, has a critical role in this $\mathrm{CO}_{2}$ hydrogenation. This catalyst can activate both $\mathrm{CO}_{2}$ and $\mathrm{H}_{2}$ so that these two substrates are ready to interact under mild conditions.

\section{Conclusions}

The mesoporous carbon synthesized using a soft-template with phloroglucinol as a carbon precursor and pluronic F-127 as a template has good characteristics to support Ni-Ga catalysts. $\mathrm{Ni-Ga/MC}$ catalyst was successfully synthesized using the impregnation method by $\mathrm{H}_{2}$ reduction at $700{ }^{\circ} \mathrm{C}$ for 2 hours. The hydrogenation reaction of $\mathrm{CO}_{2}$ on the $\mathrm{Ni}_{5} \mathrm{Ga}_{3} / \mathrm{MC}$ catalyst shows $\sim 100 \%$ selectivity to formaldehyde, with the highest yield obtained at $200{ }^{\circ} \mathrm{C}$. Increasing the temperature reaction above $200{ }^{\circ} \mathrm{C}$ results in a decrease in $\mathrm{CO}_{2}$ conversion, corresponding to the exothermic reaction conditions. Herein, both $\mathrm{Ni}$ and $\mathrm{Ga}$ metals show an important role in the $\mathrm{CO}_{2}$ hydrogenation. In $\mathrm{Ni}_{5} \mathrm{Ga}_{3} / \mathrm{MC}$ catalyst, the formation of formaldehyde and methanol products indicates the critical key of bimetallic $\mathrm{Ni}_{5} \mathrm{Ga}_{3}$ alloy formation in the application of $\mathrm{CO}_{2}$ hydrogenation.

\section{Acknowledgment}

The authors gratefully acknowledge FMIPA Universitas Indonesia for FMIPA Universitas Indonesia Research Grant contract number NKB-017/UN2.F3/HKP.05.00/2021 for funding this project and Afif $Z$. Pamungkas for setting up the catalyst reactor.

\section{References}

[1] Rafiee, A., Khalilpour, K.R., Milani, D., Panahi, M. (2018). Trends in $\mathrm{CO}_{2}$ conversion and utilization: A review from process systems perspective. Journal of Environmental Chemical Engineering, 6(5), 5771-5794. DOI: 10.1016/j.jece.2018.08.065.
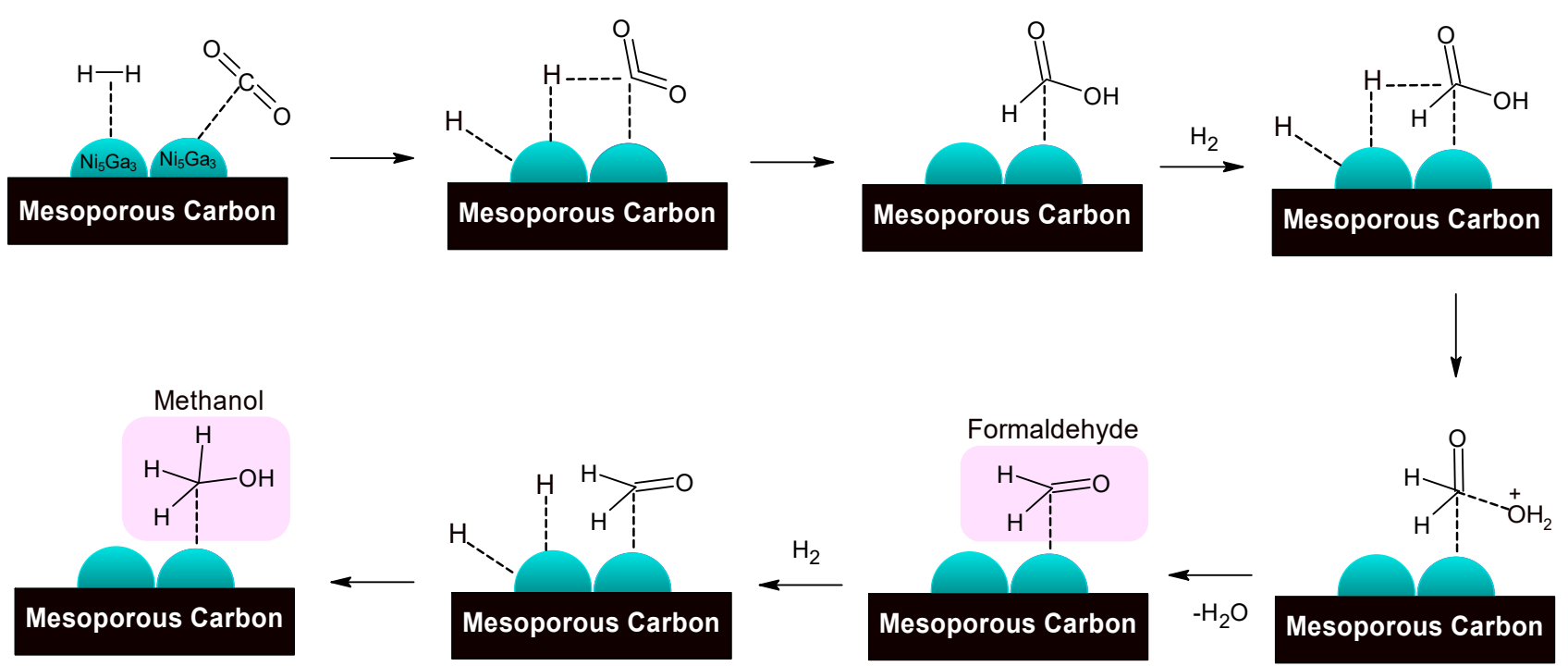

Figure 8. The proposed $\mathrm{CO}_{2}$ hydrogenation mechanism reaction on $\mathrm{Ni}-\mathrm{Ga} / \mathrm{MC}$ catalyst. 
[2] Alper, E., Orhan, O.Y. (2017). $\mathrm{CO}_{2}$ utilization: Developments in conversion processes. Petroleum, 3(1), 109-126. DOI: 10.1016/j.petlm.2016.11.003.

[3] Krajčí, M., Hafner, J. (2016). Intermetallic compounds as selective heterogeneous catal y s t s: ins ight s from DFT. ChemCatChem, 8(1), 34-48. DOI: 10.1002/cctc. 20150073 .

[4] Studt, F., Sharafutdinov, I., Abild-Pedersen, F., Elkjær, C.F., Hummelshøj, J.S., Dahl, S., Chorkendorff, I. Nørskov, J.K. (2014). Discovery of a Ni-Ga catalyst for carbon dioxide reduction to methanol. Nature Chemistry, 6(4) 320-324. DOI: 10.1038/nchem.1873.

[5] Nguyen, H.K.D., Dang, T.H., Nguyen, N.L.T., Nguyen, H.T., Dinh, N.T. (2018). Novel Ni-Ga alloy based catalyst for converting $\mathrm{CO}_{2}$ to methanol. The Canadian Society for Chemical Engineering, 96(4), 832-837. DOI: 10.1002/cjce.23006.

[6] Ahmad, K., Upadhyayula, S. (2019). Conversion of the greenhouse gas $\mathrm{CO}_{2}$ to methanol over supported intermetallic $\mathrm{Ga}-\mathrm{Ni}$ catalysts at atmospheric pressure: thermodynamic modeling and experimental study. Sustainable Energy \& Fuels, 3(9), 2509-2520. DOI: 10.1039/c9se00165d.

[7] Ahmad, K., Upadhyayula, S. (2020). Kinetics of $\mathrm{CO}_{2}$ hydrogenation to methanol over silica supported intermetallic $\mathrm{Ga}_{3} \mathrm{Ni}_{5}$ catalyst in a continuous differential fixed bed reactor. International Journal of Hydrogen Energy, 45(1), 1140-1150. D O : 10.1016/j.ijhydene.2019.10.156.

[8] Jiang, X., Nie, X., Guo, X., Song, C., Chen, J. G. (2020). Recent advances in carbon dioxide hydrogenation to methanol via heterogeneous catalysis. Chemical Reviews, 120(15), 79848034. DOI: 10.1021/acs.chemrev.9b00723.

[9] Liang, C., Li, Z., Dai, S. (2008). Mesoporous carbon materials: synthesis and modification. Angewandte Chemie International Edition, 47(20), 3696-3717. DOI: 10.1002/anie.200702046.

[10] Amelia, I., Krisnandi, Y.K., Abdullah, I. (2020). Synthesis and characterization of soft and hard templated mesoporous carbon using phloroglucinol as carbon precursor. IOP Conference Series: Materials Science and Engineering, 902(1), 012023. DOI: 10.1088/1757899X/902/1/012023.

[11] Khairani, N.S., Abdullah, I., Krisnandi, Y.K. (2020). Synthesis and characterization of NiZn/mesoporous carbon as heterogeneous catalyst for carboxylation reaction of acetylene with $\mathrm{CO}_{2}$. AIP Conference Proceedings, 2242(1), 040039. DOI: 10.1063/5.0007890.
[12] Kawigraha, A.D.H., Krisnandi, Y.K., Abdullah, I. (2020). Synthesis of impregnated nickel-mesoporous carbon and its application for reaction of acetylene with carbon dioxide. IOP Conference Series: Materials Science and Engineering, 763(1), 012040. DOI: 10.1088/1757899X/763/1/012040.

[13] Abdullah, I., Andriyanti, R., Nurani, D.A., Krisnandi, Y.K. (2021). Nickelphenanthroline Complex Supported on Mesoporous Carbon as a Catalyst for Carboxylation under $\mathrm{CO}_{2}$ Atmosphere. Bulletin of Chemical Reaction Engineering \& Catalysis, 16 (1), $111-119$. D O I : 10.9767/bcrec.16.1.9733.111-119.

[14] Gorka, J., Zawislak, A., Choma, J., Jaroniec, M. (2008). KOH activation of mesoporous carbo n s obtained by sof t templating. Carbon, 46(8), 1159-1161. DOI: 10.1016/j.carbon.2008.03.024.

[15] Chiou, J.Y., Kung, H.Y., Wang, C.B. (2017). Highly stable and active Ni-doped ordered mesoporous carbon catalyst on the steam reforming of ethanol application. Journal of Saudi Chemical Society, 21(2), 205-209. DOI: 10.1016/j.jscs.2015.10.006.

[16] Ortega-Franqueza, M., Ivanova, S., Domínguez, M.I., Centeno, M.Á. (2021). Mesoporous Carbon Production by Nanocasting Technique Using Boehmite as a Template. Catalysts, 11(9), 1132. DOI: 10.3390/catal11091132.

[17] Kumar, S., Sarau, G., Tessarek, C., Bashouti, M.Y., Hähnel, A., Christiansen, S., Singh, R. (2014). Study of iron-catalysed growth of B$\mathrm{Ga}_{2} \mathrm{O}_{3}$ nanowires and their detailed characterization using TEM, Raman and cathodoluminescence techniques. Journal of Physics D: Applied Physics, 47(43), 435101. DOI: 10.1088/0022-3727/47/43/435101.

[18] Kumar, V.B., Mastai, Y., Porat, Z.E., Gedanken, A. (2015). Chiral imprinting in molten gallium. New Journal of Chemistry, 39(4), 2690-2696. DOI: 10.1039/c4nj02081b.

[19] Li, J., Li, P., Li, J., Tian, Z., Yu, F. (2019). Highly-dispersed $\mathrm{Ni}-\mathrm{NiO}$ nanoparticles anchored on an $\mathrm{SiO}_{2}$ support for an enhanced CO methanation performance. Catalysts, 9(6), 506. DOI: 10.3390/catal9060506.

[20] Zhou, J., Huang, L., Yan, W., Li, J., Liu, C., Lu, X. (2018). Theoretical Study of the Mechanism for $\mathrm{CO}_{2}$ Hydrogenation to Methanol $\mathrm{C}$ a t a lyzed by $\mathrm{trans}-\mathrm{RuH}_{2}$ (CO)(dpa). Catalysts, 8(6), 244. DOI: 10.3390/catal8060244. 